\title{
Genetic analysis of tonic immobility in young Japanese quail (Coturnix coturnix japonica)
}

\author{
F. H. BENOFF and P. B. SIEGEL \\ Virginia Polytechnic Institute and State University, Blacksburg, Virginia 24061
}

\begin{abstract}
Data were obtained on tonic immobility from 10th-generation matings of replicated lines of Japanese quail. These lines had been selected for high and low mating ability and included the random-bred control population from which the selected lines originated. At 6 , and again at 12 days of age, each bird was subjected to uniform procedures of immobilization and was given two scores, one indicating the number of trials required to induce immobility, another the duration of induced immobility. Although there were no differences between sexes, lines were significantly different for duration and percentage incidence to the immobility response at both ages. Individuals that responded faster also exhibited longer durations of immobility, suggesting a high degree of susceptibility. Heritability estimates indicate that the additive genetic variation effecting tonic immobility is low to moderate in magnitude. These results, when taken in an evolutionary context, suggest prior natural selection for tonic immobility and indicate that this trait is associated with fitness.
\end{abstract}

From an ecological vantage point, tonic immobility may be implicated as an adaptive response to predation. Investigators have shown that the presence of a looming object (Ginsburg, Braud, \& Taylor, 1974) or simulation of the predator-prey relationship (Gallup, 1973; Gallup, Nash, Donegan, \& McClure, 1971) will prolong the immobility response. Other workers, as cited by Gallup (1974a), have noted the occurrence of tonic immobility under natural conditions and described its survival value.

Another approach to the study of tonic immobility as a behavioral trait with evolutionary significance involves the determination of the genetic components influencing the behavior. To date, two studies have been published that assess the genetic influences on tonic immobility. McGraw and Klemm (1973) found significant differences in the duration of immobility in two lines of rats that had previously been selected for maze learning capabilities. There was, however, no response to two generations of individual phenotypic selection for high and low duration of immobility. They then inbred the populations for three generations and obtained two lines that differed in the duration of immobility. In a two-way selection experiment for the duration of immobility in chickens, Gallup (1974b) reported realized heritabilities of .58 and .59 in the upwards and downwards directions, respectively. These values are unusually large for realized heritabilities.

The purpose of our experiment was to evaluate the genetic aspects of tonic 1mmobility in young Japanese quail.

\section{Subjects}

\section{METHOD}

Quail used in this experiment were from a random-bred control population $(\mathrm{C})$ and from the 10 th generation matings of replicated lines selected for high $\left(\mathrm{H}_{1}\right.$ and $\left.\mathrm{H}_{2}\right)$ and low $\left(\mathrm{L}_{1}\right.$ and

This research was supported in part by NSF Grant GB-40060.
$\mathrm{L}_{2}$ ) mating frequency (Sefton \& Siegel, 1973). The selected lines originated from the $C$ population. The birds were raised as heterosexual flocks in a modified chick battery brooder under continuous llumination. Feed and water were provided ad lib.

\section{Procedure}

At 6 and again at 12 days of age, each quail was carried by hand from its brooding pen to a testing platform located in the same room, placed on its right side, and manually restrained for $15 \mathrm{sec}$. When immobility did not occur following the first restraint, successive $15 \mathrm{sec}$ sessions were initiated with a maxtmum of five attempts. An induction number based on the number of restraints required to induce immobility was assigned to each quail. The temporal duration of immobility was measured in seconds from the time restraint was terminated to the time the chick righted itself. Individuals that failed to immobilize received an induction number of 5 and a duration score of 0 sec. Data were obtaned for 387 males and 416 females.

Each chick was in clear view of an observer who was seated approximately $1 \mathrm{n}$ from 1 . Direct eye contact between the observer and the qual was avoided because Gallup, Cummings. and Nash (1972) demonstrated that such contact has a prolonging influence on the duration of tonic immobility.

\section{RESULTS AND DISCUSSION}

Results of a factorial analysis indicated that differences among lines for duration of immobility at 6 and at 12 days of age were highly significant (Table 1 ), suggest-

Table 1

Analyses of Variance for Duration of Tonic Immobility by Age

\begin{tabular}{lrcc} 
& & & \\
Source of Variation & df & 6 Day & 12 Day \\
\hline Among Lines (L) & 4 & $108.12^{* *}$ & $148.33^{* *}$ \\
Among Hatches (H) & 1 & $164.73^{* *}$ & $725.16^{* *}$ \\
Among Sexes (S) & 1 & 52.13 & 1.55 \\
L by H & 4 & 13.64 & 30.64 \\
L by S & 4 & $38.95^{*}$ & 12.86 \\
H by S & 1 & 40.01 & 3.74 \\
L by H by S & 4 & 7.78 & 7.19 \\
Residual & 783 & 14.94 & 16.31 \\
\hline \multicolumn{4}{r}{$* 0.05$} \\
\end{tabular}


Table 2

Mean Duration (Seconds) of Immobility by Line and Age

\begin{tabular}{lll}
\hline Lines & \multicolumn{3}{c}{ Age (Days) } \\
\hline H1 & 6 & 12 \\
H2 & $82.5^{*}$ & $44.2^{*}$ \\
C & $80.8^{* * *}$ & $92.9^{* *}$ \\
L1 & $46.5^{* \dagger}$ & $41.9^{*}$ \\
L2 & $58.6 \dagger$ & $63.2 \dagger$ \\
Mean & $43.3^{*}$ & $56.9^{*} \dagger$ \\
\hline
\end{tabular}

Note-Means within a column with the same symbol are not significantly different $(p<.05)$.

Table 3

Cumulative Percentage Incidence of Tonic Immobility by Line and Age

6 Day 12 Day

Line $n$ 1st 2nd 3rd 4th 5th 1st 2nd 3rd 4th 5th

$\begin{array}{llllllllllll}\text { L1 } & 232 & 85 & 94 & 96 & 98 & 100 & 91 & 99 & 100 & 100 & 100\end{array}$

$\begin{array}{llllllllllll}\text { L2 } & 154 & 82 & 93 & 98 & 98 & 100 & 94 & 98 & 99 & 100 & 100\end{array}$

$\begin{array}{llllllllllll}\mathrm{C} & 192 & 82 & 95 & 97 & 97 & 100 & 83 & 98 & 100 & 100 & 100\end{array}$

$\begin{array}{llllllllllll}\text { H1 } & 137 & 80 & 93 & 98 & 99 & 100 & 82 & 94 & 98 & 100 & 100\end{array}$

$\begin{array}{llllllllllll}\mathrm{H} 2 & 88 & 86 & 96 & 96 & 97 & 100 & 97 & 100 & 100 & 100 & 100\end{array}$

Note-Individuals who failed to respond received an induction number of 5 with a duration of 0 sec. There were 16 such cases.

ing a genetic basis for this trait. Duncan's multiple range test was used to separate means. Rankings of lines by the size of their means indicate that there was no relationship between the duration of tonic immobility and prior selection for mating ability (Table 2). The duration of immobility increased, over age, for all lines except Line $C$. Lines $\mathrm{H}_{2}$ and $\mathrm{L}_{1}$ had the longest durations at both ages, with the rankings of the other lines shifting somwhat with age. The product moment correlation of .93 of rankings of lines at 6 and 12 days of age was significant.

The incidence of tonic immobility for lines and age groups is presented in Table 3 as the cumulative percentage incidence over five restraints. The range among lines for percentage of quail responding to the immobility reflex on the first restraint was considerably greater at 12 days ( $82 \%$ to $97 \%$ ) than at 6 days ( $80 \%$ to $82 \%$ ) of age. The range among lines narrowed by the second retraint as values approached $100 \%$. At both ages, the rankings of lines for percentage incidence on the first restraint was similar to the rankings of those lines for duration of immobility. Lines with longer mean durations of immobility had a larger proportion of birds responding on the first restraint; likewise, those with smaller mean durations had a lower incidence of immobility. These results are in agreement with those of Ratner and Thompson (1960) who found a positive correlation between the percentage of chickens responding and the duration of immobility. Percentage incidence of immobility on the first restraint increased with age, as did the duration of immobility.

There was no sexual dimorphism at either age for percentage incidence of tonic immobility. Further, there were no significant differences among sexes for duration of immobility at 6 and 12 days of age (Table 1). Mean duration of immobility was $46.3 \mathrm{sec}$ for males and $54.9 \mathrm{sec}$ for females at 6 days of age. At 12 days of age, the means were 58.4 for males and 55.6 for females, which is consistent with Borchelt and Ratner (1973) and Gallup (1974b), who reported a lack of sexual dimorphism for the trait in quail and chickens. No differences between sexes would have been expected if tonic immobility was a defensive behavior, as previously noted by Gallup (1974b).

A significant Line by Sex interaction was found at 6 days, but not at 12 days of age (Table 1). The interaction at 6 days may be attributed to the differential response of sexes in Line $L_{1}$, which was in contrast to that observed in the other lines.

Heritability estimates based on full and half sib correlations for the duration of tonic immobility at 6 and at 12 days of age are presented in Table 4, with expected mean squares in Table 5 . These estimates were obtained by using the appropriate variance components provided by a hierarchical classification analysis of variance described by King and Henderson (1954). Estimates for full sib correlations were comparable for males and females at both ages. They are composed of sizeable amounts of additive and nonadditive genetic effects, plus maternal influences. It may be argued that maternal effects are not important for these traits because the eggs were artificially incubated and the chicks brooded without the presence of their mother. Maternal influences, however, have been demonstrated for other traits where eggs and chicks were handled in this manner. Accordingly, to be conservative, we prefer to point out where the genetic effects may be possibly confounded with maternal influences.

At 6 days of age, the heritabilities from maternal and paternal half sib correlations were of the same magnitude for males, suggesting additive gene effects on duration of tonic immobility. On the other hand, for female progeny the estimates based on maternal half sib correlations were larger than those calculated from paternal half sib correlations. Heritabilities based on maternal half sib correlations, while containing an additive genic component, also provide information on nonadditive gene effects and maternal effects. In

Table 4

Heritabilities and Standard Errors for Duration of Tonic Immobility by Age and Sex

\begin{tabular}{|c|c|c|c|c|}
\hline Age & & Males & Females & Mean \\
\hline 6 Day & $\begin{array}{l}4 S \\
4 D \\
2(S+D)\end{array}$ & $\begin{array}{l}.24 \pm .24 \\
.23 \pm .36 \\
.24 \pm .15\end{array}$ & $\begin{array}{r}-.18 \pm .20 \\
.49 \pm .34 \\
.15 \pm .12\end{array}$ & $\begin{array}{l}.03 \\
.36 \\
.20\end{array}$ \\
\hline 12 Day & $\begin{array}{l}4 S \\
4 D \\
2(S+D)\end{array}$ & $\begin{array}{l}.03 \pm .23 \\
.22 \pm .38 \\
.12 \pm .15\end{array}$ & $\begin{array}{l}.65 \pm .25 \\
.03 \pm .27 \\
.34 \pm .14\end{array}$ & $\begin{array}{l}.34 \\
.13 \\
.23\end{array}$ \\
\hline
\end{tabular}


Table 5

Expected Mean Squares for Heritability Analysis

\begin{tabular}{|c|c|c|}
\hline Source of Variation & Male Progeny & Female Progeny \\
\hline Among Hatches & $\sigma_{\mathrm{e}}^{2}+2.43 \sigma_{\mathrm{d}}^{2}+4.98 \sigma_{\mathrm{s}}^{2}+40.02 \sigma_{\mathrm{l}}^{2}+188.04 \sigma_{\mathrm{h}}^{2}$ & $\sigma_{\mathrm{e}}^{2}+2.46 \sigma_{\mathrm{d}}^{2}+5.24 \sigma_{\mathrm{s}}^{2}+46.37 \sigma_{\mathrm{l}}^{2}+195.5 \sigma_{\mathrm{h}}^{2}$ \\
\hline Among Lines $w / n$ Hatches & $\sigma_{\mathrm{e}}^{2}+2.42 \sigma_{\mathrm{d}}^{2}+4.99 \sigma_{\mathrm{s}}^{2}+38.06 \sigma_{1}^{2}$ & $\sigma_{\mathbf{e}}^{2}+2.36 \sigma_{\mathrm{d}}^{2}+4.93 \sigma_{\mathrm{s}}^{2}+39.93 \sigma_{\mathbf{l}}^{2}$ \\
\hline $\begin{array}{l}\text { Among Sires } w / n \\
\text { Lines } w / n \text { Hatches }\end{array}$ & $\sigma_{\mathrm{e}}^{2}+1.98 \sigma_{\mathrm{d}}^{2}+3.66 \sigma_{\mathrm{s}}^{2}$ & $\sigma_{\mathrm{e}}^{2}+2.11 \sigma_{\mathrm{d}}^{2}+3.89 \sigma_{\mathrm{s}}^{2}$ \\
\hline $\begin{array}{l}\text { Among Dams } w / n \text { Sires } \\
w / n \text { Lines } w / n \text { Hatches }\end{array}$ & $\sigma_{\mathbf{e}}^{2}+1.78 \sigma_{\mathbf{d}}^{2}$ & $\sigma_{\mathrm{e}}^{2}+2.00 \sigma_{\mathrm{d}}^{2}$ \\
\hline $\begin{array}{l}\text { Among Full Sib } \\
\text { Progeny } w / n \text { Hatches }\end{array}$ & $\sigma_{\mathbf{e}}^{2}$ & $\sigma_{\mathrm{e}}^{2}$ \\
\hline
\end{tabular}

principle, they are supposed to be at least as large as the sire-based estimates which include additive gene effects and some epistatic deviations. The negative paternal half sib estimate for female progeny at 6 days of age may be due to the small sample size.

Heritability estimates of tonic immobility at 12 days of age also suggest that nonadditive gene action, maternal effects, or a combination of both influence this trait. Since the estimate from maternal half sib correlations for females was small, it would seem that maternal effects have been eliminated by this age. The posthatching environment of the chick also may have masked the influence of the egg environment (maternal effects). Since such would be a function of time, maternal effects would become less with increasing chronological age of the chicks.

Since heritability estimates based on full and half sib correlations are not precise, male and female est 1 mates within a sib type were pooled and the average heritability calculated. At 6 days of age, the mean estimate based on maternal half sib correlations was .33 greater than the mean estimate from paternal half sib correlations. This is indicative of sizeable maternal and/or nonadditive genetic effects with some additive gene action. By 12 days of age, maternal effects were small, if existent at all, and there were indications of considerable amounts of genetic additivity. The amount of genic additivity, however, was still considerably smaller than that indicated from realized heritabilities obtained for the domestic fowl (Gallup, 1974b).

Phenotypic correlations between tonic immobility at 6 and 12 days of age were .34 for males and .11 for females, suggesting a low to moderate positive relationship. Genetic correlations are due to either the transient effects of linkage or the more permanent effects of pleiotropy. The latter effect is more readily implicated as a cause for correlation of duration on tonic immobility at 6 and 12 days of age because the trait is being measured at both ages. The genetic correlation based on the sire and dam components of variance and covariance between tonic immobility at 6 and 12 days of age was greater than unity for males and .18 for females. This diversity suggests that the estimates may be unreliable. Accordingly, a bank of data may be needed to obtain reliable estimates of the genetic correlations between tonic immobility measured at 6 and 12 days of age in Japanese quail.

In conclusion, heritability estimates of tonic immobility indicate that nonadditive gene effects and/or maternal effects are more important than additive gene effects. Since the severity of the selection pressure to which a trait has been exposed is a direct function of its adaptive significance, behaviors most closely related to fitness will have little additive genetic variation. These results suggest that tonic immobility is a fitness trait and is therefore an adaptive behavior.

\section{REFERENCES}

Borchelt, P. L., \& Ratner, S. C Development of freezing and immobility, predation defenses, in the Bobwhite qual (Colinus virginianus). Behavioral Biology, 1973, 8, 83-92.

Gallup, G. G., Jr. Simulated predation and tonic immobility in lizards (Anolis carolmensis). Copeia, 1973, 3, 623-624.

Gallup. G. G. Jr. Animal hypnosis: Factual status of a fictional concept. Psychological Bulletin, 1974, 81, 836-853. (a)

Gallup, G. G., Jr. Genetic influences on tonjc immoblity in chickens. Animal Learning \& Behavior, 1974, 2, 145-147. (b)

Gallup, G. G., Jr., Cummings, W. H., \& Nash, R. F. The expenmenter as an independent variable in studies of animal hypnosis in chickens (Gallus gallus). Animal Behavior, 1972. 20, 166-169.

Gallup, G. G., Jr., Nash, R. F., Donegan, N. H., \& McClure, $M$. K. The immobility response. A predator-tnduced reaction in chickens. Psychological Record, $1971,21,513-519$.

Ginsburg, H. J., Braud, W. G., \& Taylor, R. D. Effect of looming objects on $1 \mathrm{mmobility}$ response in Gallinaceous birds (Gallus gallus). Journal of Comparative and Physiological Psychology, $1974,86,146-150$

King, S. C., \& Henderson, C. R Vanance components analysis in heritability studies. Poultry Science, 1954, 33, 147-154.

McGraw, C. P., \& Klemm, W. R. Genetic difference in susceptibility of rats to the immobility reflex ("anumal hypnosis"). Behavior Genetics, 1973, 3, 155-161.

Ratner, S. C. \& Thompson, R. W. Immobility reaction (fear) of domestic fowl as a function of age and prior expenence. Animal Behaviox, 1960, 8, 186-191.

Sefton, A. E., \& Siegel, P. B. Mating behavror of Japanese quall. Poultry Science, 1973,52, 1001-1007.

(Received for publication July 28, 1975; revision accepted October 10, 1975.) 